\title{
Market Microstructure: The Components of Black-Box
}

\author{
Muath Asmar (Corresponding Author) \\ Finance Section, School of Management, Universiti Sains Malaysia, 11800, Penang, Malaysia \\ Tel: 60-4-653-3888 Ext: $2531 \quad$ E-mail: muathasmar@msn.com
}

\begin{abstract}
Zamri Ahmad
Finance Section, School of Management, Universiti Sains Malaysia, 11800, Penang, Malaysia

Tel: 60-4-653-3888 Ext: 2755 E-mail: zahmad@usm.my
\end{abstract}

\begin{abstract}
During the last few decades, market microstructure has become an important discipline within the field of finance. The market microstructure literature have been enriched by theoretical, empirical and experimental studies relating to other areas of finance such as assets pricing, corporate finance, international finance and welfare. The processes and rules of exchanging securities are considered an important issue since they affect the way in which trades are determined, prices are formed and scope of asymmetric information. However, the ways of describing how exchange process occurs in the markets are varied. This paper determines the components of the market microstructure black-box in terms of trading mechanisms and regulations governing various aspects of trading process. Determining the components of the black-box allows researchers to identify and compare the themes in market microstructure and issues facing the process of trading securities. Thus, this paper may be used as a source for future research ideas in comparing the market microstructure of exchanges. It also provides necessary input to the regulatory bodies to enhance the design of better markets. Furthermore, this paper would help the investors and portfolio managers to make better trading decisions by understanding how markets work and how it regulated as well as the investors will be able to interpret how various rules affect price efficiency, liquidity, transaction costs and trading profits.
\end{abstract}

Keywords: Market Microstructure, Trading Mechanisms, Market Regulations

\section{Introduction}

Microstructure is usually very specific about the mechanism and regulation used to accomplish of trading. It has an impact on market efficiency, securities values, securities liquidity, market transparency and transaction costs. This area of finance is not new and it has long history but during the last few decades it acquired a distinct identity. The market microstructure covers the trading rules and trading system used by a market through which investors predictions of the future and their trading strategies are ultimately translated into the current assets prices and trading volumes. O'Hara (1995) has described market microstructure as the study of the process and outcomes of exchanging assets under explicit trading rules. Madhavan (2000) has defined the market microstructure as the process by which investors' latent demands are ultimately translated into prices and volumes. Spulber (1996) has provided a broader definition of market microstructure which is the study of the intermediation and the institutions of exchange. One important implication drawn from these definitions is that the market microstructure is shaped by trading mechanisms and trading regulations. Market microstructure theory challenged the traditional view of efficient market witch ignored the mechanisms by which prices of securities are formed (O'Hara, 1987). Thereof, the essential theme of the market microstructure theory is that securities prices need not fully reflect all available information because of a variety of fractions (Madhavan, 2000).

Securities markets over the entire world are currently structured in a myriad of ways in terms of trading mechanisms and regulations governing various aspects of trading. They are also transformed fundamentally and rapidly as the computerized trading of securities replaces the traditional open outcry trading (O'Hara, 2001). Determining how exactly a market is structured is an important for researchers to conduct a comparative studies in order to identify the optimal structure for trading securities in terms of market quality and efficiency (Comerton-Forde \& Rydge, 2004), and for individuals investors to understand how markets work and regulate. Thus, the individual investors will improve their trading strategies, and they can better manage the brokers, who work for them. They will also be able to predict how various rules affect price efficiency, liquidity, and trading profits (Larry Harris, 2002).

Several studies explore the microstructure of securities exchanges in the world, a region and within a country. For example, Comerton-Forde and Rydge (2004) provide a review of the market microstructure of eighteen of the world's largest and most influential stock markets. They review the market microstructure based on trading mechanisms, level of transparency, trading structures, short selling, principal trading and crossing rules. They found that there are considerable differences in microstructure between regions as well as between individual exchanges in terms of trading mechanisms and market regulations. They also contend that historical economic and political developments are of major importance in explaining these differences. In their subsequent study Comerton-Forde and Rydge (2006) review the market microstructure of ten Asia-Pacific stock exchanges with regards to market type, market linkages, market fragmentation, market makers, order priority rules, price steps, short selling, market 
transparency and price variation controls in the exchanges. They document significant differences in market design across Asia-Pacific stock exchanges. Demarchi and Foucault (2000) surveyed the changes in the market microstructure of the five largest European Stock Exchanges during the last decade of the twenty century. They describe the basic design of the trading systems and the criteria of segmenting the stock used by exchanges in terms of trading mechanisms with regard to type of stocks, order size and time of the trading. They found that the trading systems are similar whereas electronic order-driven markets are utilized in these markets. Further, they show that there are considerable differences between the exchanges with regard to the order flow consolidation, role of dealers, market transparency and clearing and settlement. Additionally, there are major differences in the trading rules including the price determination, order types and priority, trading halts and circuit-breakers, and tick size among the exchanges. In addition, Xu (2000) describes the microstructure of the Shanghai Securities Exchange and Shenzhen Securities Exchange; especially the trading method used in these markets regarding market type, trading sessions and price discovery, order types, and trading unit. They show that Chinese stock exchanges adopted a centralized computerized order matching system; however, differences between these exchanges regarding listing rules are exist. Such studies have taken a snapshot on the market microstructure in a specified time. However, in reality securities markets make major changes in their trading rules and new methods of trading arise with surprising frequency. This necessitates a comprehensive guideline to determine the components of the Black-Box of the microstructure. These components can be classified according to the trading mechanism and trading regulation, which shape the structure of market.

The needs for a standardized guide to allow researchers to identify and compare the differences between securities markets in a certain time or individual market over different times motivate us to conduct this research. The purpose of this descriptive paper is to identify and classify the components of the market microstructure by reviewing the prominent and important relevant studies on the market microstructure.

The remaining of this paper is organized as follows: Section two provides a brief summary of the important relevant studies on the market microstructure. Section three discusses the trading mechanism. Section four discusses trading regulation. Section five is the conclusion of the paper.

\section{Literature on Market Microstructure}

The market microstructure research is important for illustrating the behavior of prices and markets, which has direct influence on the market regulation, and on the design and formulation of trading mechanisms. O'Hara (1995) provides a detailed survey of the theoretical literature and considers the standard reference for the economic theory of market microstructure. Madhavan (2000) surveyed the literature on the microstructure studies, building on empirical, theoretical and experimental studies relating to markets and trading. Harris (2002) provides a detailed conceptual overview about trading, the people who trade securities and contracts, the marketplaces where they trade, and the rules that govern trading; his focus is on the practitioners not on the academic literature. Easley and O'Hara, (2003) surveyed the studies on the microstructure regarding the microstructure factors and asset price dynamics. Biais, et al. (2005) provide a comprehensive review analyzing the price formation and trading process, interrelation between institutional structure, strategic behavior, prices and welfare. Hasbrouck (2007) provides a detailed integrated introduction to the most important models of empirical market microstructure studies.

Several studies have focused on a comparison between two trading methods in a similar span of time. For instance, based on the differences in execution methods applied in the opening and closing transactions, Amihud and Mendelson (1987) have compared the behavior of call market and continuous auction returns on NYSE stocks. They have found that call market return variance is higher than continuous auction return variance. Comerton-Forde (1999) has compared the opening method used by the Australian Stock Exchange and the Jakarta Stock Exchange. She has documented that the trading method affects the securities liquidity and volatility. Theissen (1999) has compared the transaction cost in the trading mechanism used by Frankfurt Stock Exchange where trading conducted in floor and in electronic trading system at the same time. He has reported that the bid-ask spreads, tends to be larger on the floor than electronic trading system. Additionally, Chow, et al. (1996) have investigated the price and volume pattern around the point of mechanism switch from floor to automated system. The results indicated that the trading volume on the floor is more than that of automated system around the switch. Based on these results, they suggested that the traders tend to transact on the floor that may exist around the switch from floor to automated system. The forgoing mentioned studies have focused on the differences between two trading methods employed in the trading process. On the other hand, several studies have taken into accounts the differences in trading regulation. For example, Subrahmanyam (1994) examined the impact of the circuit breaker regulatory tool on market participants trading decisions and consequently on market liquidity and price variability. He showed that the circuit breaker may increase price variability and the probability of the price that cross the circuit breaker bounds. This takes place if the price is very close to the breaker limit and if agents place a high value on their desire to trade. Wong, et al. (2009) have investigated the magnet effects of price limit rules on the Shanghai Stock Exchange. They have found that security prices move towards limit bounds at faster rates and with increased volatility and higher trade frequency. Moreover, Onnela, et al. (2009) have studied the effect of changes in tick size on asset returns. They have proved that the traders do not use all price fractions as it is allowed by the tick size. This leads to a clustering of prices on certain fractions and a reduction in effective tick size and subsequently this phenomenon could potentially affect the 
distribution of securities return.

Based on the studies in market microstructure reviewed above, it is plausible to classify the microstructure components according to the trading mechanism and trading regulation. Trading mechanism implies the method of accomplishing the trading process, while trading regulation dictates how and when orders can be submitted and processed. This classification of market microstructure components has twofold justifications. First, the securities markets that employ similar trading mechanism could be dissimilar with regard to trading regulation. For instance, securities exchanges such as Australian Stock Exchange, Bursa Malaysia, Tokyo Stock Exchange and Swiss Exchange operate a fully automated order driven trading system. However, the trading regulations that govern the trading process are varied in these exchanges. The second justification is that the changing in the market regulations can be simply implemented by securities exchanges. On the other hand, the changing in the trading mechanisms requires real investment which takes time to be implemented.

\section{Trading Mechanisms}

Trading mechanisms refer to the methods of trading securities. Trading mechanisms are determined by several dimensions including market type, price discovery, order forms and degree of transparency as illustrated in figure 1.

\subsection{Market Type}

Securities market type has three dimensions which are degree of continuity, reliance on market makers and degree of automation (Madhavan, 2000).With regard to the degree of continuity, there are two types of market: the first one is the 'call market' where selling and buying orders are grouped together during an interval period of time and transact at single price, which equates the quantity supplied to the quantity demanded. The second one is the continuous auction market, where selling and buying orders are executed whenever submitted. The executing price represents the highest price that a buyer is willing to pay and the lowest price that a seller is willing to sell Chang, et al. (1999). With respect to the reliance on market makers, securities exchange considered as quote-driven market where prices are determined from quotations made by market makers or specialists. While securities exchange considered as order-driven market or auction market where prices are determined by the publication of orders to buy or sell shares via public investors without market makers' intermediation (Madhavan, 2000).

Concerning the degree of automation, trading mechanisms can operate either on the floor or by means of electronic systems. Regarding the first type, trading mechanism relies on an open outcry method where exchange uses face to face verbal and hands signal. In the second type, trading mechanism employs an electronic trading system where participants key in the orders.

With these multidimensional market types a plethora of choices for the trading of securities are available to the securities exchanges. Therefore, most of the securities markets are actually hybrids, involving dealers, clearings, one- and two-sided auctions, and bilateral bargaining (Hasbrouck, 2007). Market microstructure researches have proved that the market type affect the performance of markets and prices of securities. For example, Huang and Stoll (1996) have investigated the executing costs in order-driven market as represented by NYSE and quote-driven market as represented NASDAQ. Their results indicate that the cost of executing transactions is higher on quote-driven market than on the order-driven market. Blennerhassett and Bowman (1998) have examined the changing of open outcry trading to an electronic screen trading system at New Zealand Stock Exchange. They found that the changing of market type lead to lower execution costs. Pagano and Schwartz (2003) have investigated the impact of utilizing call auctions at market closings on market quality at Euronext Paris. They revealed that the utilizing call auctions have a positive effect on market quality. Chelley-Steeley (2008) has examined the effect of introducing a closing call auction on market quality at the London Stock Exchange. She found that the introduction of call auction improves the market quality concerning the speed of price adjustments to new information and with respect to prices efficiency.

\subsection{Trading Sessions}

A trading session is a defined period of time, consists of several phases from the preopining phase to the closing phase where the trading of securities may take place. Each phase within trading session implies a process of trading and price discovery under explicit trading rules.

Trading in the securities exchange occurs frequently using periodic or continues auctions. It is open for specific days a week. Exchanges could splits the trading day up into a morning and afternoon session. Each trading session goes through a series of phases which are usually opening, continuous trading, preclosing, closing and trading at last. In addition, trading could include preopening phases. In each phase of trading specific orders types are allowed to be entered, modified or deleted, these orders are batched for execution at a certain execution price calculated by the trading system or set by the market makers. It is important to identify the process of price discovery in each trading phases and the rule of order priority whereas transactions are taken place.

Trading sessions is an important concern to securities prices. In line with this view, Ito and Lin (1992) have examined the differences of trading sessions on New York Stock Exchange and Tokyo Stock Exchange. They found that lower volatility on the Tokyo Stock Exchange when the market is closed for the lunch break and lower volatility around the noon hour in New York when the market is open. 


\subsection{Order Forms}

A trader in stock market can contact a brokerage firm to place an order, which represents the intent of the trader to sell or buy a specific stock listed in the secondary market. In reality, traders have several options when it comes to placing an order to buy or sell securities with regards to order types. Orders are contingent on a variety of conditions concerning quantity, price and time, whereas the most commonly used types of order are the market and limit orders.

A market order is a quantity contingent order used to immediately buy or sell a stock at the best bid or ask price currently available in the market. Market orders are always guaranteed to be executed as long as there are active buyers or sellers in the market. The market order guarantees the quantity but not the price, especially in fast moving markets. The order in fast moving markets might be executed at different price from real-time obtained price. This drawback in market order can be overcome by placing a limit order. Limit order is price contingent order to buy or sell a stock at a specific price outside the range of the current quotes. This type of orders allows traders to control and guarantee the price at which the trade is executed, but it is not guaranteed to be executed unless the specified price is reached.

Another price contingent order is stop order which allows trader to protect profits or stop loss. The stop order is an order to buy or sell a stock when the price of the stock reaches a specified price known as the stop price. When a current price reaches stop price, the stop order becomes a market order. A buy stop order is always placed at a price above the current market price typically used to limit a loss or protects a profit on short sales. A stop sell order is always placed below the current market price and it is used to stop loss or protects profits.

Stop limit order is a price contingent order to buy or sell a stock that combines the features of a stop order and a limit order. This order turns into a limit order when the stop price is attained. Stop limit order gives traders more control of when and at what price the order will be executed.

Additionally, there are other types of orders used to control price, quantity or execution of trade, such as fill or kill order, which is a market or limit order to buy or sell a certain stock for a specified quantity immediately, in case the order is not executed in its entirety, it will be automatically cancelled. Another type orders is called all or nothing, which is a limit order used to a buy or sell full amount of quantity or not at all, in case there is insufficient quantity at a specified price the all or nothing order unlike the fill or kill order, it is not cancelled and it remains on the order book as a limit order.

All orders are day orders, that is, valid on and for the day when they are placed, unless otherwise specified. However, the trader can place good till cancelled order usually is a limit or stop order, which it remains valid until executed, cancelled or expired after a specified period. Moreover the trader can specify at what time the order will be executed. For example a trader can place market on opening order in the pre opining trading phase, this order would be executed at the opening of the trading session at an opening price; also the trader can place market on closing order in the pre closing trading phase, this order will be executed at the closing phase at closing price.

The types of order available at security exchange affect the performance of the market and thus the investors profits. Placing an order seems be the most decisive decision an investors make through the trading process regarding to the order types. Easley and O'Hara (1991) have examined the effect of order forms on security prices. They revealed that the possibility to trade using alternative order forms affect the performance of the market. In addition, Harris and Hasbrouck (1996) have investigated order forms execution performance. They found that the limit order placement strategies most commonly used by NYSE investors perform better than market orders.

\subsection{Market Transparency}

Market usually is transparent when high quantity and quality of information regarding current and past prices, quotes, depths, volumes and the identities of market participants are rapidly available to the public. In this sense 'market transparency refers to the ability of market participants to observe information about the trading process' (O'Hara, 1995). When discussing market transparency, it can be divided into pre-and post-trading dimension. Pre-trading transparency refers to the dissemination of information about the limit-order book, bid and ask quotations, orders flow, identities of market participants, market depth. Post-trading transparency refers to the availability and velocity of dissemination of the information to the public about trading details such as volumes, prices, trader identities and transaction time. Generally, electronic markets that communicate in real time the bids and offers of buyers and sellers and the prices of executed trades are considered highly transparent. On the other hand, the dealer markets often have no publicly visible bids or offers, nor any trade reporting, and are therefore usually considered opaque (Hasbrouck, 2007).

Several studies have investigated the effect of market transparency on market quality. However, the results are inconclusive. Pagano and Roell (1996) have investigated whether greater transparency improves market liquidity. They found that greater transparency lead to reduce the trading costs for uninformed traders. In addition, Chung and Chuwonganant (2009) have examined the effect of changing pretrade transparency on market quality. Their results indicate that both transaction cost and return volatility declined significantly after increasing market transparency. On the other hand, Bloomfield and O'Hara (1999) have investigated the effects of trade and quote dissemination on bid-ask spreads. Their results revealed that increased transparency increases opening bid-ask spreads. In addition, 
Madhavan et al. (2005) have investigated the effects of disclose the limit order book to the public on market liquidity. One of the important conclusions that emerges from their analysis is that the increase in transparency has increased the execution costs in terms of the bid-ask spread.

\section{Market Regulations}

Market Regulations refer to the rules of trading securities defined by securities market to control various aspects of trading process, such as the rules of order priority, tick size and spread, listing, trading unit, price thresholds, trading status, short selling and off-market trading as illustrated in Figure 1.

\subsection{Rules of Order Priority}

Matching of the security orders priority is given according to certain criteria determined by securities exchange. Since the quantity contingent orders match at the best available prices, they are given priority and executed before price contingent orders. Demarchi and Foucault (2000) contend that the price priority and then time priority is most favorable as it leads to price competition among traders. For instance, price and time priority rules take place in the continuous auction markets where market rules often require the highest of bid or lowest of ask price order received to be executed first. In case of two bids or asks are received at the same price, the first entered bid or ask order is given priority and is executed first. Unlike the continuous auction markets, the dealer markets do not operate under price and time priority rules. In this type of markets, it is a sine qua non for brokerages to seek the preferable prices for trader orders.

\subsection{Rules of Tick Size and Spread}

The minimum change allowed by the stock exchanges in the price, a security could go either up or down, is known as a tick size. Angel (1997) contend that tick size rules are useful in explaining the prices variety across countries. Tick size could be in decimals or fractions such as 'eighths or sixteenths'; it could also be fixed or varied within different price ranges. Tick size is an important factor determining the bid-ask spread, which is the difference between a security's bid price and it's ask price. Lau and McInish (1995) confirm that the reduction in the tick size decreased bid-ask spreads significantly and therefore reduced transactions costs. Ke, et al. (2004) revealed that increases tick size leads to increased the bid-ask spreads and volatility.

The size of the spread is attributed to liquidity and transparency of the market, that is, more liquidity and transparency in the market decrease the bid-ask spreads. Ascioglu, et al. (2010) argue that higher minimum tick size would generate high unnecessarily transactions costs. While lower minimum tick size may lead to low market liquidity. In quote driven markets, dealers buy stocks at the ask price and sell at the bid price. Thus, the size of the bid-ask spread is proportional to the size of the dealer's profit.

\subsection{Rules of Listing}

Securities exchanges have listing requirements to approve listing shares of companies in accordance with listing rules. Securities exchanges have different sections where companies would be listed. Securities are allocated to a particular section of market whereby different trading mechanism and trading rules are carried out based on a number of criteria such as company size, disclosure levels, liquidity and trading activities. Biddle and Saudagaran (1989) contend that the financial disclosure levels are an important determinant of firms to list their securities on foreign exchanges. Huddart, et al. (1998) argue that lowering the listing requirement securities to attract new abroad listing would increases the trading costs to liquidity traders. The question of what makes some stock markets more attractive than others from the viewpoint of companies? is addressed by Pagano, et al. (2001). They found that the companies are preferred to be listed in more liquid and larger markets, and in markets where many companies from the same industry are listed. In addition, the companies are more likely to be listed in markets with better investor protection, and in countries with more efficient courts and bureaucracy. In contrast, the decision of listing is not associated with stringent accounting standards.

\subsection{Rules of a Trading Unit}

Trading of securities in exchanges could be conducted in a standard trading unit which is a number of securities that is generally accepted for ordinary trading purposes on the exchanges. However, trading securities could be conducted in odd-lot which is the quantity that differs from a standard trading unit. Securities exchanges usually employ different trading units of listed companies subject to trading prices. Amihud, et al. (1999) revealed that a reduction in the trading unit greatly increases the liquidity of securities and leads to a significant increase in the securities prices.

\subsection{Rules of Price Thresholds (Limits)}

A price threshold refers to the range of price movement (maximum price increases or decreases) from the previous closing price permitted by securities exchange during one trading session or one trading day. Kim and Rhee (1997) questioned the effectiveness of price limits and found that the price limits leads to increases price volatility, delays in equilibrium price discovery and disturb trading activity. Furthermore, Kim (2001) found that price limits caused more market volatility. Ryoo and Smith (2002) contend that using price limits leads to market inefficiency by prevents equity prices from following a random walk process. Chan, et al. (2005) found that employing price threshold increases the transaction costs and do not improve price discovery. 


\subsection{Rules of Trading Status}

Securities exchanges use specified rules in certain circumstances that require ceasing the matching of one stock or securities group. Such a process usually anticipates a news announcement or corrects an order imbalance. Bhattacharya and Spiegel (1998) revealed that suspensions of trading occur when the company announces impending news or the market maker observes a severe order imbalance. Implementing trading status rules would increase the market efficiency by giving all investors equal opportunities to evaluate news and make either buying, selling or holding decisions which are based on the arrival of new information.

\subsection{Rules of Short Selling}

When an investor anticipates that the price of a certain stock will rise in the future, buying and holding the security could be the best strategy. Conversely, when an investor believes that the price of a certain stock will decrease in the future, selling the security could be considered as the best strategy. In this case if an investor does not hold the stock, he/she can sell in short, which means that he/she borrows an amount of stocks from the broker and sells it in the market hoping that the prices will go down. Then the investor can buy that amount from the exchange and give it back to the broker. Thus the difference between the sell price and buy price would be the investor profits or losses.

Since short sellers possess important information and their trades are important accomplishments affecting stock prices efficiency (Boehmer, et al., 2008). Securities exchanges implemented restricted rules regarding the short selling, in some exchanges short selling is not allowed, while it is permitted in others. Ko and Lim (2006) suggest that short selling does not disturb trading activity, but adequate to provides market liquidity.

\subsection{Rules of Off-Market Trading}

Off-market trading refers to the transaction stocks of listed companies which occur outside a formal securities exchange. Off-market transactions are conducted through negotiation rather than an auction system. The reason for using off-market trading is usually to transact big block of stock without affecting the stock prices. Booth, et al. (2002) found that off-market trading tend to have lower information content and lower price impacts than trading securities in formal exchange.

\section{Conclusion}

This paper determines the components of the market microstructure black-box. Market microstructure includes the trading mechanisms and regulations as the main components. Trading mechanisms determined by market type, price discovery, order forms and degree of transparency, whereas market regulations includes the rules of order priority, tick size and spread, listing, trading unit, price thresholds, trading status, short selling and off-market trading. Taking into account the components of market microstructure is important for conducting research in market microstructure and its related to other area of finance. More importantly as long as the research in market microstructure plays an important role in providing a necessary input to the issues of how to design and conduct the trading, therefore, taking into consideration the components of market microstructure is important for addressing such issues in future research and enhancing the design of markets as well as improving the trading strategies of individual investors.

\section{Acknowledgement}

The authors would like thank the editor and anonymous reviewers for helpful comments and suggestions. We also would like to thank the participants of the International Conference on Business and Economic Research (ICBER) 2010, for their feedback on earlier version of this paper. In addition, the correspondent author would like to thank the Universiti Sains Malaysia (USM) for offering USM Fellowship.

\section{References}

Amihud, Y. \& Mendelson, H. (1987). Trading Mechanisms and Stock Returns: An Empirical Investigation. The Journal of Finance, 42(3), 533-553.

Amihud, Y., Mendelson, H. \& Uno, J. (1999). Number of Shareholders and Stock Prices: Evidence from Japan. The Journal of Finance, 54(3), 1169-1184.

Angel, J. J. (1997). Tick Size, Share Prices, and Stock Splits. The Journal of Finance, 52(2), 655-681.

Ascioglu, A., Comerton-Forde, C. \& McInish, T. H. (2010). An examination of minimum tick sizes on the Tokyo Stock Exchange. Japan and the World Economy, 22(1), 40-48.

Bhattacharya, U. \& Spiegel, M. I. (1998). Anatomy of a Market Failure: NYSE Trading Suspensions (1974-1988). Journal of Business \& Economic Statistics, 16(2), 216-226.

Biais, B., Glosten, L. \& Spatt, C. (2005). Market microstructure: A survey of microfoundations, empirical results, and policy implications. Journal of Financial Markets, 8(2), 217-264.

Biddle, G. C. \& Saudagaran, S. M. (1989). The Effects of Financial Disclosure Levels on Firms' Choices among Alternative Foreign Stock Exchange Listings. Journal of International Financial Management \& Accounting, 1(1), 55-87.

Blennerhassett, M. \& Bowman, R. G. (1998). A change in market microstructure: the switch to electronic screen trading on the New Zealand stock exchange. Journal of International Financial Markets, Institutions and Money, 
8(3-4), 261-276.

Bloomfield, R. \& O'Hara, M. (1999). Market transparency: who wins and who loses? Review of Financial Studies, $12(1), 5-35$.

Boehmer, E., Jones, C. M. \& Zhang, X. (2008). Which Shorts Are Informed? The Journal of Finance, 63(2), 491-527.

Booth, G. G., Lin, J.-C., Martikainen, T. \& Tse, Y. (2002). Trading and Pricing in Upstairs and Downstairs Stock Markets. The Review of Financial Studies, 15(4), 1111-1135.

Chan, S. H., Kim, K. A. \& Rhee, S. G. (2005). Price limit performance: evidence from transactions data and the limit order book. Journal of Empirical Finance, 12(2), 269-290.

Chang, R. P., Hsu, S.-T., Huang, N.-K. \& Rhee, S. G. (1999). The Effects of Trading Methods on Volatility and Liquidity: Evidence from the Taiwan Stock Exchange. Journal of Business Finance \& Accounting, 26(1-2), 137-170.

Chelley-Steeley, P. L. (2008). Market quality changes in the London Stock Market. Journal of Banking \& Finance, 32(10), 2248-2253.

Chow, E. H., Lee, J.-H. \& Shyy, G. (1996). Trading mechanisms and trading preferences on a 24-hour futures market: A case study of the Floor/GLOBEX switch on MATIF. Journal of Banking \& Finance, 20(10), 1695-1713.

Chung, K. H. \& Chuwonganant, C. (2009). Transparency and market quality: Evidence from SuperMontage. Journal of Financial Intermediation, 18(1), 93-111.

Comerton-Forde, C. (1999). Do trading rules impact on market efficiency? A comparison of opening procedures on the Australian and Jakarta Stock Exchanges. Pacific-Basin Finance Journal, 7(5), 495-521.

Comerton-Forde, C. \& Rydge, J. (2004). A Review of Stock Market Microstructure. Sydney: Securities Industry Research Centre of Asia-Pacific.

Comerton-Forde, C. \& Rydge, J. (2006). The current state of Asia-Pacific stock exchanges: A critical review of market design. Pacific-Basin Finance Journal, 14(1), 1-32.

Demarchi, M. \& Foucault, T. (2000). Equity Trading Systems in Europe: A Survey of Recent Changes. Annales d'Économie et de Statistique, 60, 73-115.

Easley, D. \& O'Hara, M. (1991). Order Form and Information in Securities Markets. The Journal of Finance, 46(3), 905-927.

Easley, D. \& O'Hara, M. (2003). Chapter 17 Microstructure and Asset Pricing Handbook of the Economics of Finance (Vol. Volume 1, Part 2, pp. 1021-1052): Elsevier.

Harris, L. (2002). Trading and Exchanges: Market Microstructure for Practitioners: Oxford University Press.

Harris, L. \& Hasbrouck, J. (1996). Market vs. Limit Orders: The SuperDOT Evidence on Order Submission Strategy. The Journal of Financial and Quantitative Analysis, 31(2), 213-231.

Hasbrouck, J. (2007). Empirical Market Microstructure: The Institutions, Economics, and Econometrics of Securities Trading. New York: Oxford University Press.

Huang, R. D. \& Stoll, H. R. (1996). Dealer versus auction markets: A paired comparison of execution costs on NASDAQ and the NYSE. Journal of Financial Economics, 41(3), 313-357.

Huddart, S. J., Brunnermeier, M. K. \& Hughes, J. S. (1998). Disclosure Requirements and Stock Exchange Listing Choice in an International Context. SSRN eLibrary.

Ito, T. \& Lin, W.-L. (1992). Lunch break and intraday volatility of stock returns : An hourly data analysis of Tokyo and New York stock markets. Economics Letters, 39(1), 85-90.

Ke, M.-C., Jiang, C.-H. \& Huang, Y.-S. (2004). The impact of tick size on intraday stock price behavior: evidence from the Taiwan Stock Exchange. Pacific-Basin Finance Journal, 12(1), 19-39.

Kim, K. A. (2001). Price limits and stock market volatility. Economics Letters, 71(1), 131-136.

Kim, K. A. \& Rhee, S. G. (1997). Price Limit Performance: Evidence from the Tokyo Stock Exchange. The Journal of Finance, 52(2), 885-901.

Ko, K. \& Lim, T. (2006). Short selling and stock prices with regime switching in the absence of market makers: The case of Japan. Japan and the World Economy, 18(4), 528-544.

Lau, S. T. \& McInish, T. H. (1995). Reducing tick size on the Stock Exchange of Singapore. Pacific-Basin Finance Journal, 3(4), 485-496.

Madhavan, A. (2000). Market microstructure: A survey. Journal of Financial Markets, 3(3), 205-258.

Madhavan, A., Porter, D. \& Weaver, D. (2005). Should securities markets be transparent? Journal of Financial Markets, 8(3), 265-287.

O'Hara, M. (1987). Trading Mechanisms and Stock Returns: An Empirical Investigation: Discussion. The Journal of 
Finance, 42(3), 554-555.

O'Hara, M. (1995). Market Microstructure Theory Blakwell Publishers, USA.

O'Hara, M. (2001). Overview: market structure issues in market liquidity. Paper presented at the BIS workshop.

Onnela, J.-P., Tyli, J. \& Kaski, K. (2009). Tick size and stock returns. Physica A: Statistical Mechanics and its Applications, 388(4), 441-454.

Pagano, M., Randl, O., Rell, A. A. \& Zechner, J. (2001). What makes stock exchanges succeed? Evidence from cross-listing decisions. European Economic Review, 45(4-6), 770-782.

Pagano, M. \& Roell, A. (1996). Transparency and Liquidity: A Comparison of Auction and Dealer Markets with Informed Trading. The Journal of Finance, 51(2), 579-611.

Pagano, M. S. \& Schwartz, R. A. (2003). A closing call's impact on market quality at Euronext Paris. Journal of Financial Economics, 68(3), 439-484.

Ryoo, H.-J. \& Smith, G. (2002). Korean stock prices under price limits: variance ratio tests of random walks. Applied Financial Economics, 12(8), 545 - 553.

Spulber, D. F. (1996). Market Microstructure and Intermediation. The Journal of Economic Perspectives, 10(3), $135-152$.

Subrahmanyam, A. (1994). Circuit Breakers and Market Volatility: A Theoretical Perspective. The Journal of Finance, 49(1), 237-254.

Theissen, E. (1999). Floor Versus Screen Trading: Evidence from the German Stock Market. SSRN eLibrary.

Wong, W. K., Liu, B. \& Zeng, Y. (2009). Can price limits help when the price is falling? Evidence from transactions data on the Shanghai Stock Exchange. China Economic Review, 20(1), 91-102.

Xu, C. K. (2000). The microstructure of the Chinese stock market. China Economic Review, 11(1), 79-97.

\begin{tabular}{|l|l|}
\hline Order Priority \\
\hline Tick Size and Spread \\
\hline Listing
\end{tabular}

Figure 1. The components of the market microstructure black-box. 